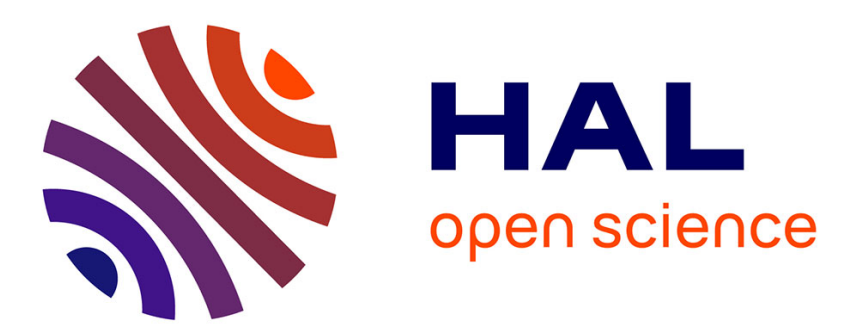

\title{
An equilibrium search model of the French dual market for medical services
}

\author{
Damien Besancenot, Radu Vranceanu
}

\section{To cite this version:}

Damien Besancenot, Radu Vranceanu. An equilibrium search model of the French dual market for medical services. 2017. hal-01574648

\section{HAL Id: hal-01574648 \\ https://essec.hal.science/hal-01574648}

Preprint submitted on 16 Aug 2017

HAL is a multi-disciplinary open access archive for the deposit and dissemination of scientific research documents, whether they are published or not. The documents may come from teaching and research institutions in France or abroad, or from public or private research centers.
L'archive ouverte pluridisciplinaire HAL, est destinée au dépôt et à la diffusion de documents scientifiques de niveau recherche, publiés ou non, émanant des établissements d'enseignement et de recherche français ou étrangers, des laboratoires publics ou privés. 


\section{E \\ ESS EC \\ BUSINESS SCHOOL}

\section{AN EQUILIBRIUM SEARCH MODEL OF \\ THE FRENCH DUAL MARKET FOR MEDICAL SERVICES}

\section{RESEARCH CENTER DAMIEN BESANCENOT, RADU VRANCEANU ESSEC WORKING PAPER 1709}

JULY 2017 
June 6,2017

\title{
An equilibrium search model
}

\section{of the French dual market for medical services \\ Damien Besancenot* and Radu Vranceanu ${ }^{\dagger}$}

\begin{abstract}
The French market for specialist physician care has a dual structure, including a sector 1 with regulated fees, and a sector 2 where physicians can freely choose fees. Patients who undergo a sequential search process for the best medical offer develop a reservation fee decision rule. We analyzed physicians' decisions to work in sector 1 or in sector 2 , and their choice of fee in sector 2 . The model features several pure strategy equilibria that can be ordered with respect to patient welfare. Policy implications follow.
\end{abstract}

JEL Classification: D83, I11, I18.

Keywords: Equilibrium search, Medical fee dispersion, Dual market, Regulation.

\footnotetext{
${ }^{*}$ University of Paris Descartes and LIRAES, 45 rue des Saints Pères, 75270 Paris, E-mail: damien.besancenot@parisdescartes.fr

†ESSEC Business School and THEMA, 1 Av. Bernard Hirsch, 95032 Cergy. E-mail: vranceanu@essec.fr.
} 


\section{Introduction}

Out of the 223,571 physicians active in France in 2016 as recorded by the Statistical Office of the Health Ministry (DRESS), 47,4\% were self-employed, and another 10,8\% operated under a mix of self-employment and contract based services. ${ }^{1} \quad$ There is no ex-ante allocation of patients to physicians; patients are free to choose their physician. In particular, in the market for specialists, patients will search for the physician that best matches their expectations. A similar search process can be observed with respect to newcomers in a city who search for a general practitioner.

This paper aims to analyze how trade frictions can alter the equilibrium fees posted by specialist physicians in a decentralized market for medical services, and to identify the implications for patient welfare, given the specific organization of the French health care sector.

Since 1980, self-employed specialist physicians in France have been allowed to choose between performing their medical practice in a heavily regulated "sector 1 " or under the much looser regulation in "sector $2 "{ }^{2} \quad$ In $2014,43 \%$ of the specialist physicians were working in sector 2 , and this proportion is steadily increasing. ${ }^{3} \quad$ Fees charged by physicians in sector 1 are determined by the National Health Insurance in an agreement with physicians, and they are covered in full. The first part of the fee is covered by the universal public insurance (better known as the "Social Security") up to a predetermined amount. The remaining amount is covered by complementary insurance as provided by several private insurance companies, to which more than $96 \%$ of the population had access in 2010. ${ }^{4}$ Physicians working in sector 2 can freely choose their medical fees. According to Article 53 of the Public Health Law, they should set their fees with "a sense of measure". Nonetheless, fees charged in sector 2 are increasing every year; in 2014, the premium charged in sector 2 compared to sector 1 represented on average of 23 euros/medical care, which

\footnotetext{
1 Data extracted on Mai 26, 2017 on http://drees.social-sante.gouv.fr.

2 Between 1980 and early 1990, general practitioners could also opt for working in sector 2. Carrère (1991) reveals that $80 \%$ of the GPs decided to remain in sector 1 . As a consequence of these past choices, $6 \%$ of the total GPs were still working in the sector 2 in 2012.

3 See CISS Collectif Interassociatif sur la Santé, Observatoire citoyen des restes à charge en santé / 21 mai 2015, www.santeclair.fr/web/site/santeclair.fr /files/ 150521_dp_ depassementshonorairesmedicaux toujourshausse_1.pdf

4 In 2004, a reform of complementary insurance contributed to further extend the coverage. See Saliba and Ventelou 2007 for an analysis of the reform.
} 
is $35,7 \%$ of the total fee. In general, patients will pay for the difference between the fee in sector 2 and the fee in sector 1 from their own pockets, although private insurance can also cover part of it (Clerc et al., 2012).

Moving from sector 1 to sector 2 is an important decision for the physician. In addition to the possible negative impact on the number of forthcoming patients, moving to sector 2 comes with additional costs. Access to sector 2 is restricted to physicians with a proven high skill level, as attested by experience or prestigious degrees. Furthermore, physicians in sector 1 receive a subsidy for their contribution to the retirement system which is not granted to physicians in sector 2. Finally, sector 2 physicians will in general bear some higher "representation costs", such as a better location or a more expensive office.

As more and more physicians chose to move to sector 2, patient associations are complaining that finding a doctor in sector 1 has become extremely hard, and that the excessive fees charged in sector 2 make access to medical care increasingly difficult. ${ }^{5}$ These worrisome trends prompted in 2013 the Health Ministry and the National Health Insurance to encourage physicians in sector 2 to sign special agreements (referred to as Contrats d'Accès aux Soins), where they voluntarily agree to cap their fees (on average) and in turn receive additional benefits. These contracts further evolved in 2017, and are now referred to as OPTAM (Option Pratique Tarifaire Maitrisée) agreements. ${ }^{6} \quad$ While this scheme is relatively complex, in brief, physicians can agree to charge fees that are at most twice the fees in sector 1 for a predetermined percent of their service. In turn, private complementary insurance is allowed to cover these "moderate" fees in full.

This paper uses an equilibrium search model to analyze the choice of sector and price decisions of self-employed physicians, and the consequences of these choices for patients. The use of a search model appears as a natural choice, as the information acquisition costs are quite high in the market for medical services, in particular for those services that involve complex diagnostic and treatment procedures (Rochaix, 1989; Mehrez et al., 1995; Emons, 2001) ${ }^{7}$.

\footnotetext{
5 See http://www.leciss.org/newsletter/test-selection-contenu-6

6 Can be translated as the "option to post moderate fees".

7 Traditional search literature has acknowledged that the production of price information in decentralized markets is a time consuming, costly phenomenon. See for instance: Stigler, 1960; McCall, 1970; Diamond, $1971 ; 1987$.
} 
Patients are assumed to be heterogenous with respect to their willingness to pay for the medical service and search for the best medical offer in a sequential mode. Physicians decide on the sector of activity. Furthermore, should they chose sector 2, they must decide on the best fee level. The key policy variable is the regulated fee in sector 1 , which traditionally has been a subject of controversy between the patients' association, the medical unions, the National Health Insurance and the government. The model presents several pure strategy equilibria that can be ranked with respect to patient welfare. In many cases, physicians can extract a significant part of the patients' surplus. Dunn and Shapiro (2014) revealed that in the US, medical fees are higher in areas where the spatial concentration of physicians' is higher. Our model shows that trade frictions can increase the market power of physicians even if the market concentration is low. This model will allow us to shed some light on the consequences of imposing caps on the sector 2 fees as recently implemented in France.

As a limitation of this short paper, the quality of the medical service is assumed to be invariant. An extension which would allow for a heterogenous health care quality could be developed along the lines of the equilibrium search model with price and quality differentiation by Besancenot and Vranceanu (2003). In addition, in building the model we assumed that the cost of moving from sector 1 to sector 2 is identical for all physicians. If physicians have different costs form moving from sector 1 to sector 2 the model could generate a mixed strategy equilibrium where some physicians choose the sector 1 and the others chose the sector 2. However, in this more realistic setting the essential decision on whether physicians in sector 2 post high or low fees would be guided by the same rationale as in the simplified setting.

\section{The model}

\subsection{Main assumptions}

We consider the market for a given medical service. The problem features a unit mass of patients and a unit mass of physicians. In line with classical assumptions in the literature, patients engage in a sequential search process, meeting one physician per period (McCall 1971). We assume that search costs are merely the psychological cost of delaying the cure process, and involve a discount 
factor $\beta<1$. In the context of medical services, this discount factor incorporates the probability that the disease aggravates quickly and can thus be very low in some specific situations. In this dynamic context, patients optimally determine a "reservation fee". They will accept all offers charging a fee lower than this reservation fee and keep searching at least one more period if the fee exceeds the reservation fee.

As a consequence of differences in preferences, perceptions, health insurance coverage or income, patients differ in their willingness to pay for a medical service (Nay et al., 2016). It goes beyond the purpose of the paper to study the determinants of this willingness to pay. We assume that there are $\lambda$ type- $H$ patients characterized by a high willingness to pay $\theta^{H}$ and $(1-\lambda)$ type- $L$ patients with a low willingness to pay $\theta^{L}$. Let $p^{j}$ be the reservation fee of the type- $j$ patient, with $j \in[L, H]$.

Physicians can chose between practising in the "regulated" sector 1 and in the "free" sector 2. We assume that the medical service has the same quality regardless of the practitioner. This is a plausible assumption if one takes into account the pure medical service, as a patient should obtain the right treatment regardless of the sector. However, the paper abstracts from the possibility of horizontal differentiation, where physicians in sector 2 can provide better nonessential services, such as better comfort during the waiting time, a reduced waiting time, etc. ${ }^{8}$

Let $p$ denote the fee charged by physicians. This fee depends on the sector, the prevailing regulation, and the optimal choice of the physician. In the general framework, we assume that in sector 1 , the medical fee is determined by the National Health Insurance in agreement with physicians, and will be denoted $\bar{p}$. In France, this regulated fee $\bar{p}$ is fully reimbursed to the patient by the Social Security and complementary private insurance.

In sector 2 , physicians freely determine the fee ${ }^{9}$. Depending on the "target" patients (low or high willingness to pay), they should set as an optimal price either the reservation price $p^{L}$, or the reservation price $p^{H}$. They have no reason to set a fee lower than the reservation fee because patients of a given type would accept the higher reservation fee. The public and private health

\footnotetext{
${ }^{8}$ Such second-order differences can also justify differences in medical fees, in a horizontal differentiation model.

${ }^{9}$ We will study later on the constraints on fees in sector 2
} 
insurances will cover a fraction $(1-\mu)$ of the difference between the sector 1 fee and the actual fee. In general, $\mu>0$, thus patients must pay from their pockets the difference $\mu(p-\bar{p})$.

The instantaneous utility of a type- $j$ patient who accepts the physician's offer $p$ is:

$$
u^{j}(p)=\theta^{j}-\mu(p-\bar{p}), \text { with } j \in[L, H], \text { and } p \in\left[\bar{p}, p^{L}, p^{H}\right]
$$

In sector 1 , the offer is $p=\bar{p}$, thus $u^{j}(\bar{p})=\theta^{j}$.

The production cost of the medical service is normalized to zero. Physicians who chose to work in Sector 2 must bear some additional costs, both fixed (related to degrees and certifications) and variable (such as the higher social contributions and the higher representation costs). To keep the model simple, we discard the additional fixed cost and consider that there is only a constant cost $t$ per patient.

Let $s$ denote the frequency of physicians who choose to work in sector 1 . Thus, $(1-s)$ is the frequency of physicians who chose to work in sector 2 .

Let $l$ denote the frequency of physicians in sector 2 who post the low fee $p^{L}$; thus; $(1-l)$ is the frequency of physicians in sector 2 who post the fee $p^{H}$.

Figure 1 presents the physicians' decision tree:

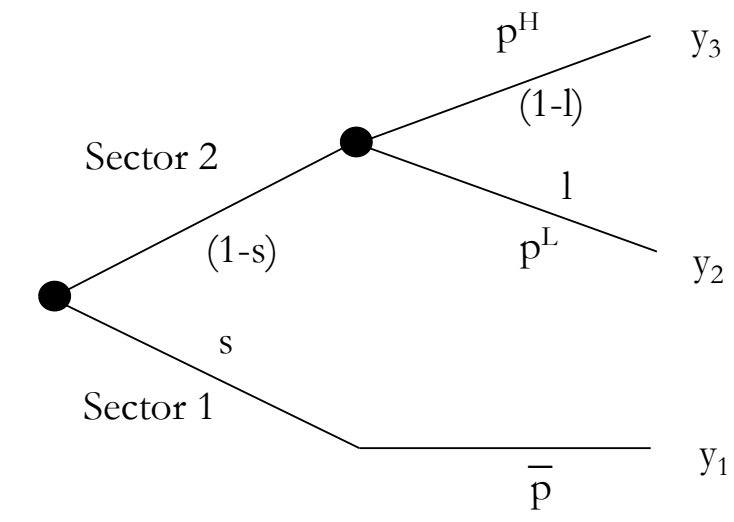

Figure 1: Physicians' Decision Tree

An equilibrium of the game is defined as a situation where patients chose their reservation price in an optimal way given the physicians' best strategies, and physicians chose their best sector and price strategy given patients' optimal strategy. Hence, an equilibrium is characterized 
by the reservation prices $p^{L}$ and $p^{H}$ and the pair of equilibrium frequencies $\Omega=(s, l)$. Note that in equilibrium, the actual frequencies $s$ and $l$ should match patients' beliefs, $s=\operatorname{Pr}[$ Physician works in sector 1] and $l=\operatorname{Pr}\left[\right.$ Physician posts $p^{L} \mid$ Physician works in sector 2]. To keep the notation simple, hereafter $s$ and $l$ will denote both the frequencies of the respective strategies and the beliefs of the patients.

\section{$2.2 \quad$ Reservation fees}

At each period, patients can find either a physician in sector 1 offering the regulated fee $\bar{p}$ (with frequency $s$ ), a physician in sector 2 posting the low fee $p^{L}$ (with the frequency $l(1-s)$ ), or a physician in sector 2 posting the high fee $p^{H}$ (with the frequency $(1-s)(1-l)$ ).

To determine the reservation fee of the type- $L$ patient, we acknowledge that the patient must be indifferent between accepting that offer and obtaining the associated instantaneous utility, or rejecting that offer and "obtaining" the discounted expected utility from an open sequence of similar searches. Denoting by $V^{L}(p)$ the value function of the type- $L$ patient, his reservation fee $\left(p^{L}\right)$ must verify the indifference condition:

$$
\begin{aligned}
\theta^{L}-\mu\left(p^{L}-\bar{p}\right) & =\beta\left\{s V^{L}(\bar{p})+(1-s)\left[l V^{L}\left(p^{L}\right)+(1-l) V^{L}\left(p^{H}\right)\right]\right\} \\
& =\beta\left\{s \theta^{L}+(1-s)\left[l\left(\theta^{L}-\mu\left(p^{L}-\bar{p}\right)\right)+(1-l)\left(\theta^{L}-\mu\left(p^{L}-\bar{p}\right)\right)\right]\right\} \\
& =\frac{\beta s}{1-\beta(1-s)} \theta^{L} .
\end{aligned}
$$

This result is obtained by acknowledging that the type- $L$ patient who gets an offer $\left(p^{H}\right)$ continues to search insofar as the posted fee exceeds his reservation fee. Given the definition of the reservation fee, his discounted expected utility from the search activity is equal to $\left(\theta^{L}-\mu\left(p^{L}-\bar{p}\right)\right)$. The implicit definition of the reservation fee is:

$$
\mu\left(p^{L}-\bar{p}\right)=\left(\frac{1-\beta}{1-\beta(1-s)}\right) \theta^{L}
$$

Obviously, $p^{L}>\bar{p}$, the reservation fee of $L$-type patients is higher than the regulated fee in sector 1.

Following a similar reasoning, and denoting by $V^{H}(p)$ the value function of a type- $H$ patient, 
his reservation fee $p^{H}$ must verify:

$$
\begin{aligned}
\theta^{H}-\mu\left(p^{H}-\bar{p}\right) & =\beta\left\{s V^{H}(\bar{p})+(1-s)\left[l V^{H}\left(p^{L}\right)+(1-l) V^{H}\left(p^{H}\right)\right]\right\} \\
& =\beta\left\{s \theta^{H}+(1-s)\left[l\left(\theta^{H}-\mu\left(p^{L}-\bar{p}\right)\right)+(1-l)\left(\theta^{H}-\mu\left(p^{H}-\bar{p}\right)\right)\right]\right\} \\
& =\frac{\beta[s+(1-s) l] \theta^{H}-\beta l(1-s) \mu\left(p^{L}-\bar{p}\right)}{1-\beta(1-s)(1-l)}
\end{aligned}
$$

Replacing $\mu\left(p^{L}-\bar{p}\right)$ by its expression in Eq (3), we obtain:

$$
\theta^{H}-\mu\left(p^{H}-\bar{p}\right)=\frac{\beta[s+(1-s) l] \theta^{H}-\beta l(1-s)\left(\frac{1-\beta}{1-\beta(1-s)}\right) \theta^{L}}{1-\beta(1-s)(1-l)}
$$

or

$$
\begin{aligned}
\mu\left(p^{H}-\bar{p}\right) & =\theta^{H}-\frac{\beta[s+(1-s) l] \theta^{H}-\beta l(1-s)\left(\frac{1-\beta}{1-\beta(1-s)}\right) \theta^{L}}{1-\beta(1-s)(1-l)} \\
& =\left[\frac{1-\beta}{1-\beta(1-s)(1-l)}\right]\left[\theta^{H}+\frac{\beta l(1-s)}{1-\beta(1-s)} \theta^{L}\right]
\end{aligned}
$$

Both spreads $\left(p^{L}-\bar{p}\right)$ and $\left(p^{H}-\bar{p}\right)$ are increasing functions in the private coverage rate $(1-\mu)$. In other words, if the coverage rate increases, this pushes up the two reservation prices. Because this variable is not essential for the model, in the following we will assume that $\mu=1$, i.e., the patient covers from his pocket the whole difference between the sector 2 fee and the sector 1 regulated fee. Then, the two reservation prices have the expressions:

$$
\begin{aligned}
p^{L} & =\bar{p}+\left[\frac{1-\beta}{1-\beta(1-s)}\right] \theta^{L} \\
p^{H} & =\bar{p}+\left[\frac{1-\beta}{1-\beta(1-s)(1-l)}\right]\left[\theta^{H}+\frac{\beta l(1-s)}{1-\beta(1-s)} \theta^{L}\right]
\end{aligned}
$$

\subsection{Equilibria}

In this game, physicians present three possible pure strategies. We list below these strategies and the associated net payoff $(y)$. We recall that $t$ represents the (constant) marginal cost that physicians who choose sector 2 must bear.

Strategy 1: Work in sector 1 (and charge the regulated fee $\bar{p}$ ). The expected net income associated with this strategy is:

$$
y_{1}(\bar{p})=\bar{p}
$$


Strategy 2: Work in sector 2 and charge the low fee $p^{L}$. This offer can be accepted by all patients.

The net income is:

$$
y_{2}\left(p^{L}\right)=(\bar{p}-t)+\left[\frac{1-\beta}{1-\beta(1-s)}\right] \theta^{L} .
$$

Strategy 3: Work in sector 2 and charge the high fee $p^{H}$. This offer can be accepted only by the $H$-type patients, which represent only a proportion $\lambda$ of all patients. The expected net income is:

$$
y_{3}\left(p^{H}\right)=\lambda\left(p^{H}-t\right)=\lambda\left\{(\bar{p}-t)+\frac{(1-\beta)}{1-\beta(1-s)(1-l)}\left[\theta^{H}+\frac{\beta(1-s) l}{1-\beta(1-s)} \theta^{L}\right]\right\} .
$$

We can show that the game presents three pure strategy equilibria.

Table 1 presents the equilibrium net income and the net income if the physician deviates from the equilibrium strategy, as well as the equilibrium conditions and their range of existence, given

\begin{tabular}{|c|c|c|c|}
\hline & $\begin{array}{l}\text { All work in sector } 1 \\
\text { and charge } \bar{p}\end{array}$ & $\begin{array}{l}\text { All work in sector } 2 \\
\text { and charge } p^{L}\end{array}$ & $\begin{array}{l}\text { All work in sector } 2 \\
\text { and charge } p^{H}\end{array}$ \\
\hline Equilibrium & $s=1, l$ not defined & $s=0, l=1$ & $s=0, l=0$ \\
\hline$y_{1}(\bar{p})$ & $\bar{p}$ & $\bar{p}$ & $\bar{p}$ \\
\hline$y_{2}\left(p^{L}\right)$ & $y_{2}\left(p^{L}\right)=(\bar{p}-t)+(1-\beta) \theta^{L}$ & $\bar{p}-t+\theta^{L}$ & $\bar{p}-t+\theta^{L}$ \\
\hline$y_{3}\left(p^{H}\right)$ & $\lambda\left[(\bar{p}-t)+(1-\beta) \theta^{H}\right]$ & $\lambda\left[(\bar{p}-t)+(1-\beta) \theta^{H}+\beta \theta^{L}\right]$ & $\lambda\left(\bar{p}-t+\theta^{H}\right)$ \\
\hline condition 1 (c1) & $y_{1}(\bar{p})>y_{2}\left(p^{L}\right)$ & $y_{2}\left(p^{L}\right)>y_{1}(\bar{p})$ & $y_{3}\left(p^{H}\right)>y_{1}(\bar{p})$ \\
\hline condition $2(\mathrm{c} 2)$ & $y_{1}(\bar{p})>y_{3}\left(p^{H}\right)$ & $y_{2}\left(p^{L}\right)>y_{3}\left(p^{H}\right)$ & $y_{3}\left(p^{H}\right)>y_{2}\left(p^{L}\right)$ \\
\hline $\mathrm{c} 1 \rightarrow \operatorname{cost} t$ & $t>(1-\beta) \theta^{L}$ & $t<\theta^{L}$ & $t<\theta^{H}$, otherwise $p_{3}<0$ \\
\hline $\mathrm{c} 2 \rightarrow$ fee $\bar{p}$ & $\bar{p}>p_{1}=\frac{\lambda}{1-\lambda}\left[(1-\beta) \theta^{H}-t\right]$ & $\bar{p}>p_{2}=t+\frac{\lambda\left[(1-\beta) \theta^{H}+\beta \theta^{L}\right]-\theta^{L}}{(1-\lambda)}$ & $\left\{\begin{array}{l}\bar{p}<p_{4}=\frac{\lambda}{(1-\lambda)}\left(\theta^{H}-t\right) \\
\bar{p}<p_{3}=t+\frac{\lambda \theta^{H}-\theta^{L}}{(1-\lambda)}\end{array}\right.$ \\
\hline Equilibrium price & $\bar{p}$ & $p^{L}=\bar{p}+\theta^{L}$ & $p^{H}=\bar{p}+\theta^{H}$ \\
\hline Patient surplus & $\theta^{L}+\lambda\left(\theta^{H}-\theta^{L}\right)$ & $\lambda\left(\theta^{H}-\theta^{L}\right)$ & 0 \\
\hline
\end{tabular}
$\bar{p}$ and $t$.

Table 1.Pure Strategy Equilibria

The last row indicates the patient surplus for each equilibrium, determined as: 


$$
\begin{aligned}
& W(\bar{p})=(1-\lambda) \theta^{L}+\lambda \theta^{H}=\theta^{L}+\lambda\left(\theta^{H}-\theta^{L}\right) ; \\
& W\left(p^{L}\right)=(1-\lambda)\left(\theta^{L}-\left(p^{L}-\bar{p}\right)\right)+\lambda\left(\theta^{H}-\left(p^{L}-\bar{p}\right)\right)=\lambda\left(\theta^{H}-\theta^{L}\right) ; \\
& W\left(p^{H}\right)=(1-\lambda)\left(\theta^{L}-\left(p^{L}-\bar{p}\right)\right)+\lambda\left(\theta^{H}-\left(p^{H}-\bar{p}\right)\right)=0 .
\end{aligned}
$$

If the cost $t$ is too large, either strategy 2 or both strategies 2 and 3 cannot be equilibrium strategies. If $t$ is too small, strategy 1 cannot be an equilibrium strategy. For the sake of parsimony we will analyze only the most general case where all strategies are feasible, which requires the cost condition:

$$
(1-\beta) \theta^{L}<t<\theta^{L}
$$

Table 2 presents the order of critical fees depending on the parameter $\lambda$, which, we recall, represents the proportion of type-H patients.

\begin{tabular}{|l|l|l|}
\hline & & Condition \\
\hline$p_{3}<p_{4}$ & $\Leftrightarrow$ & $t<\theta^{L}$ (assumed to be fulfilled) \\
\hline$p_{2}<p_{3}$ & & always fulfilled \\
\hline$p_{1}<p_{2}$ & $\Leftrightarrow$ & $\lambda>\lambda_{2}=\frac{\theta^{L}-t}{\beta \theta^{L}}$ \\
\hline$p_{1}<p_{3}$ & $\Leftrightarrow$ & $\lambda>\lambda_{3}=\frac{\theta^{L}-t}{\beta \theta^{H}}$ \\
\hline$p_{1}<p_{4}$ & $\Leftrightarrow$ & always fulfilled \\
\hline
\end{tabular}

Obviously, depending on $\lambda$, we have three cases:
a) $p_{1}<p_{2} \Leftrightarrow \lambda_{2}<\lambda$
b) $p_{2}<p_{1}<p_{3} \Leftrightarrow \lambda_{3}<\lambda<\lambda_{2}$
c) $p_{3}<p_{1} \Leftrightarrow \lambda<\lambda_{3}$.

\subsection{Discussion}

We now analyze the most plausible case where the number of patients with a high willingness to pay is not very large $\lambda<\lambda_{3}=\frac{\theta^{L}-t}{\beta \theta^{H}}$. The other cases are not very different, they just extend the range of $\bar{p}$ for which the sector 1 equilibrium is feasible, and thus extends the scope for multiple equilibria.

Figure 2 presents the regioning of equilibria. 


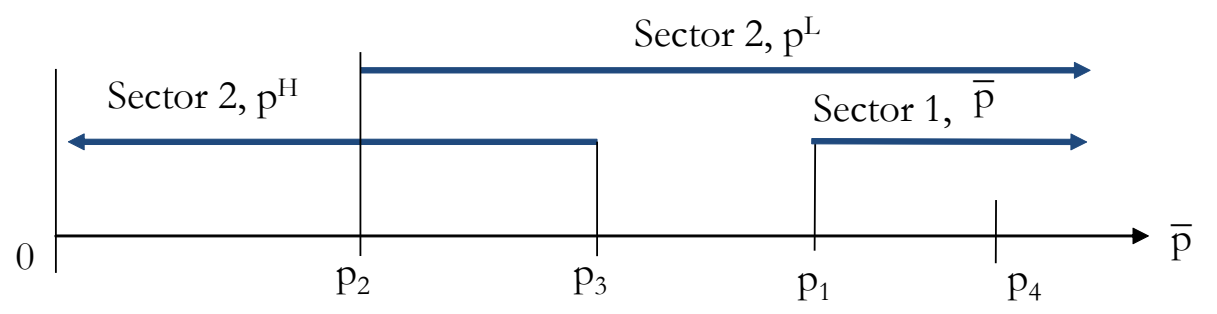

Figure 2: The Equilibrium Regioning (for $\lambda<\lambda_{3}$ )

1. If $\bar{p}<p_{2}$, only the equilibrium where all physicians work in sector 2 and post the high fee $\left(p^{H}\right)$ can emerge.

2. If $p_{2}<\bar{p}<p_{3}$, the game presents a typical configuration of multiple equilibria; both pure strategy equilibria in which all physicians choose sector 2 (and either set the fee $p^{H}$ or the fee $p^{L}$ ) can occur.

In fact, for $p_{2}<\bar{p}<p_{3}$ the game also features a mixed strategy equilibrium where all physicians chose sector $2(s=0)$ yet $l^{\prime}$ choose $p^{L}$ and $\left(1-l^{\prime}\right)$ choose $p^{H}$. The equilibrium $l^{\prime}$ can be inferred from the condition $y_{2}\left(p^{L} \mid s=0\right)=y_{3}\left(p^{H} \mid s=0\right)$. After some calculations, its expression is:

$$
l^{\prime}=\frac{(1-\beta)}{\beta(1-\lambda)}\left[\frac{\lambda \theta^{H}-\theta^{L}-(\bar{p}-t)(1-\lambda)}{\theta^{L}+\bar{p}-t}\right]
$$

We can observe that $d l^{\prime} / d \bar{p}<0$, and that $l^{\prime}=1$ for $\bar{p}=p_{2}$ and $l^{\prime}=0$ for $\bar{p}=p_{3}$. If this equilibrium prevails, the higher the regulated fee $\bar{p}$, the greater the proportion of physicians $\left(1-l^{\prime}\right)$ that will post the high price $p^{H}$.

3. If the Health authority aims to make sure that the "bad" equilibrium $p^{H}$ is ruled out for sure, they should impose a fee (slightly) above $\bar{p}=p_{3}=t+\frac{\lambda \theta^{H}-\theta^{L}}{(1-\lambda)} \cdot{ }^{10}$ In this case, physicians post $p^{L}=\bar{p}+\theta^{L}=t+\frac{\lambda \theta^{H}-\theta^{L}}{(1-\lambda)}+\theta^{L}$ and obtain a positive profit margin $p^{L}-t=\frac{\lambda\left(\theta^{H}-\theta^{L}\right)}{(1-\lambda)}$, representative of their market power in a market with trade frictions. The larger the frequency $\lambda$, the higher the margin. Patient welfare is $\lambda\left(\theta^{H}-\theta^{L}\right)$.

4. Policymakers might aim to make sure that the sector 1 equilibrium, ensuring the largest patient surplus, is also feasible. For so doing the government should push the regulated price up to $\bar{p}=p_{1}=\frac{\lambda}{1-\lambda}\left[(1-\beta) \theta^{H}-t\right]$. Such a higher regulated fee is not innocuous, as it would increase

\footnotetext{
${ }^{10}$ For $p_{3}<\bar{p}<p_{1}$ only the equilibrium where physicians charge the fee $p^{L}=\bar{p}+\theta^{L}$ exists.
} 
the total budget of the National Health Insurance, and the taxes needed to finance it.

5. Unfortunately, for $\bar{p} \geq p_{1}$ both equilibria that serve the whole patient market are feasible and, on pure theoretical grounds, it is difficult to state which of the two will prevail. One intuitively appealing refinement is Pareto-dominance, where we can assume that physicians will prefer the equilibrium where they obtain the highest profit. If all physicians choose sector 1 , their profit margin is $y_{1}(\bar{p})=\bar{p}$; if all work in sector 2 and post $p^{L}$ their profit margin is $y_{2}\left(p^{L}\right)=p^{L}-t=$ $\bar{p}+\theta^{L}-t$. Because $\theta^{L}-t>0$, this criterion for equilibrium selection suggests that the sector 2 equilibrium is most likely to prevail.

In general, systems with multiple equilibria are highly unstable, as changes in patient beliefs, themselves related to the economic outlook of the sector or to policy reforms, can prompt physicians to move from one strategy to another. Our simple model cannot capture the dynamic of change. Furthermore, the assumption according to which all physicians present the same cost of moving from sector 1 to sector 2 explains why pure strategy equilibria are prevalent. Should we relax this assumption and allow the cost $t$ to follow a standard statistical distribution, the same logic would allow the emergence of equilibria with a proportion $0<s<1$ of physicians choosing sector 1 .

6. Finally, we can use the model to analyze policy reforms such as the OPTAM agreement as presented in the Introduction. Physicians who accept this contract agree to maintain fees to maximum $200 \%$ of the sector 1 fees. It is realistic to assume that the regulation sets a cap on the highest fees in the market. More precisely, let us denote the new regulated price in sector 2 by $p^{\circ}$, with $p^{L}<p^{\circ}<p^{H}$. The National Health Insurance agreed that complementary private insurance schemes fully cover this fee, while they can cover only $\mu\left(p^{H}-\bar{p}\right)$ if the physician applies $p^{H}$. We have seen that without the cap, $p^{H}$ will be accepted only by the $\lambda$ "premium" patients (with a higher willingness to pay). Because the fee is fully reimbursed, now all patients can accept this offer, which makes it extremely interesting for the physician. However, there is a big catch in this measure, because no physician has the incentive to post $p^{L}$. After the adoption of the measure in 2016, there is a documented trend among specialists in sector 2 to push up their fees, which can be interpreted in light of the model as a move from $p^{L}$ to $p^{\circ}$. 


\section{Conclusion}

The market for medical services in France has an original two-sector structure. Physicians working in sector 1 must charge a "regulated" fee determined by centralized negotiations between the National Health Insurance and physicians' unions, while physicians working in sector 2 can freely decide on their fees. Specialized physicians can choose the sector in which they perform their medical practice. Potential patients can freely choose their physicians, and when needed, they undertake a standard search process for the best offer. This paper introduces a simple equilibrium search model to analyze the dual market for specialist physicians in France. Search models explicitly take into account the cost of producing price information in decentralized markets. Our analysis revealed that this market organization is prone to multiple equilibria with the inherent instability related to these analytical structures. In this context, changes in patients' beliefs can result in large swings of physicians from one sector to another, and even changes from a low to a high fee equilibrium.

We studied in depth the case where the proportion of patients with a high willingness to pay is relatively small. The analysis shows that there is a regulated price that rules out the most inefficient equilibrium where all physicians charge a very high reservation price. For this particular regulated fee, physicians still make positive profits as they prefer to work in sector 2 (but post a low fee). If the Health authority wants to make possible the best equilibrium from the patients' perspective where all physicians work in sector 1 , then it must raise the sector 1 regulated fee even further. Unfortunately, these higher fees do not guarantee the emergence of sector 1 equilibrium. The steadily increasing proportion of physicians opting for sector 2 as observed over the last thirty years in France can be interpreted as a slow transition from the sector 1 equilibrium to the sector 2 equilibrium, inherently reducing patient welfare. In light of our analysis, raising the regulated fee in sector 1 might not reverse this trend. Furthermore, caps on the highest fees posted in sector 2 with full reimbursement as recently enforced by the French Health authorities can also be an inefficient measure, as it would prompt all physicians to choose this fees, including those who initially favoured the lower fees.

Acknowledgement 1 The authors are grateful to Gérard de Pouvourville for his suggestions and 
remarks that helped them to improve their analysis.

\section{References}

Besancenot, Damien and Radu Vranceanu, 2004, Quality and price dispersion in an equilibrium search model, Journal of Economics and Business, 56 (2), pp. 99-116.

Carrère MO, 1991, The reaction of private physicians to price deregulation in France. Social Science and Medicine, 33. pp. 1221-1228.

Clerc, Isabelle, L'Haridon, Olivier, Paraponaris, Alain, Protopopescu, Camelia, and Ventelou, Bruno, 2012. Fee-for-service payments and consultation length in general practice: a work-leisure trade-off model for French GPs. Applied Economics, 44 (25), pp. 3323-3337.

Diamond, Peter A., 1971, A model of price adjustment, Journal of Economic Theory, 3, pp. 156-168.

Diamond, Peter A., 1987, Consumer differences and prices in a search model, Quarterly Journal of Economics, 102, pp. 429-436.

Dunn, Abe, and Adam Hale Shapiro, 2014, Do physicians possess market power? Journal of Law and Economics 57 (1), pp. 159-193.

Emons, Winnad, 2001, Credence goods monopolists. International Journal of Industrial Organization, 19 (3), pp. 375-389.

Mehrez, Abraham, Y. Yuan and Amiram Gafni, 1995, The search for information - A patient perspective on multiple opinions, European Journal of Operational Research, 85 (2), pp. 244-262. McCall, John J., 1970, Economics of information and job search, Quarterly Journal of Economics, 84, pp. 113-126.

Nay, Olivier, Béjean, Sophie, Benamouzig, Daniel, Bergeron, Henri, Castel, Patrick, and Ventelou, Bruno, 2016. Achieving universal health coverage in France: policy reforms and the challenge of inequalities. The Lancet, 387 (10034), pp. 2236-2249.

Rochaix, Lise, 1989, Information assymetry and search in the market for physicians' services, Journal of Health Economics 8, pp. 53-84.

Saliba, Bérengère, and Ventelou, Bruno, 2007. Complementary health insurance in France Who 
pays? Why? Who will suffer from public disengagement?. Health Policy, 81 (2), pp. 166-182.

Salop, Steven and Joseph Stiglitz, 1977, Bargains and ripoffs: a model of monopolistically competitive price dispersion, Review of Economic Studies, 44, pp. 493-510

Stigler, George, 1961, The economics of information, Journal of Political Economy, 69, pp. 213225 . 


\begin{tabular}{|c|c|c|c|c|}
\hline $\begin{array}{l}\text { ESSEC Business School } \\
3 \text { avenue Bernard-Hirsch } \\
\text { CS } 50105 \text { Cergy } \\
95021 \text { Cergy-Pontoise Cedex } \\
\text { France } \\
\text { Tel. + } 33 \text { (0) } 134433000 \\
\text { www.essec.edu }\end{array}$ & $\begin{array}{l}\text { ESSEC Executive Education } \\
\text { CNIT BP } 230 \\
92053 \text { Paris-La Défense } \\
\text { France } \\
\text { Tel. }+33 \text { (0) } 146924900 \\
\text { www.executive-education.essec.edu }\end{array}$ & $\begin{array}{l}\text { ESSEC Asia-Pacific } \\
5 \text { Nepal Park } \\
\text { Singapore } 139408 \\
\text { Tel. +65 } 68849780 \\
\text { www.essec.edu/asia }\end{array}$ & $\begin{array}{l}\text { ESSEC Africa-Atlantic } \\
\text { Plage des Nations } \\
\text { Sidi Bouknadel } \\
\text { Rabat-Salé } \\
\text { Morocco } \\
\text { Tel. +212 (0)5 } 30104019 \\
\text { www.essec.edu }\end{array}$ & $\begin{array}{l}\text { ESSEC Africa-Indian Ocean } \\
\text { Royal Road, Pierrefonds } \\
\text { Mauritius } \\
\text { Tel. + } 2304012400 \\
\text { www.essec.edu } \\
\text { www.icsia.mu }\end{array}$ \\
\hline
\end{tabular}

\section{- MOROCCO}

\section{Contacts}

Centre de Recherche

+33 (0)134433091

research.center@essec.fr

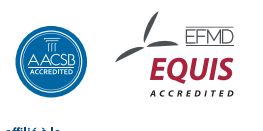

Cí CCI PARIS ILE-DE-FRANCE

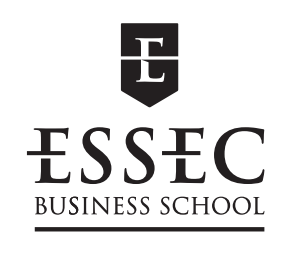

